\title{
PRECONCEITO E EXCLUSÃO: UMA POSSIBILIDADE DE LEITURA DO CONTO "AQUELES DOIS", DE CAIO FERNANDO ABREU
}

\author{
Alan Dayniel Soares, Fernando Teixeira Luiz \\ Universidade do Oeste Paulista - UNOESTE, Faculdade de Artes Ciências Letras e Educação de Presidente Prudente, \\ Licenciatura em Letras, Presidente Prudente, SP. E-mail: alandayniel.s@gmail.com, fer.luiggi@hotmail.com.
}

\section{RESUMO}

A sociedade atual ainda está carregada de preconceitos e de valores conservadores, baseando-se neles para julgar e rotular alguém. São vistos muitos casos de violência física e moral direcionados aos homossexuais nos contextos nacionais e internacionais. Faz-se necessária, então, a problematização da homofobia e o debate acerca da urgência de combater tais atos de preconceito, discutir sobre o tema a fim de conscientizar as pessoas e torná-las mais humanas, capazes de perceber de forma autônoma a importância da empatia, do sentimento de compaixão para com o próximo. Visto isso, o presente trabalho tem o propósito de contextualizar a homofobia e problematizar o conto "Aqueles Dois", de Caio Fernando Abreu. A pesquisa teve como suporte teórico as contribuições de Coelho (2000), Butler (2003) e, sobretudo, Candido (2013). A rigor, a pesquisa sinalizou a presença do preconceito da sociedade da década de 1980, sendo muito presente o heterocentrismo e a homofobia.

Palavras-chave: homofobia, preconceito, literatura, análise, teoria.

\section{PREJUDICE AND EXCLUSION: A POSSIBILITY OF READING OF THE TALE “THOSE TWO", OF CAIO FERNANDO ABREU}

\begin{abstract}
Today's society is still fraught with prejudices and retrograde values, relying on them to judge and label someone. There are many cases of physical and moral violence against homosexuals in national and international contexts. It is necessary to discuss homophobia and discuss the urgency of combating such acts of prejudice, to discuss the subject in order to raise awareness and make people more human, capable of realizing themselves the importance of empathy, the feeling of compassion for others. Given this, the present work has the purpose of contextualizing homophobia and humanizing the readers through the analysis of the story "Those Two" of Caio Fernando Abreu. The research had as theorical support the contributions of Coelho (2000), Butler (2003) and Candido (2013). Stricly speaking, the research signaled the society's prejudice in the 1980s, with heterocentrism and homophobia all too present.
\end{abstract}

Keywords: homophobia, prejudice, literature, analysis, theory. 


\section{INTRODUÇÃO}

A análise realizada do conto "Aqueles Dois" tem como principais objetivos verificar o contexto de homofobia presente no conto, com o intuito de debater o preconceito existente na sociedade da década de 1980. A rigor, os primeiros movimentos LGBTs tiveram início no Brasil na década de 1970, tornando-se mais enfáticos na década de 1980 devido ao surto da AIDS, embora sua visibilidade tenha ganhado força apenas em 1990, clamando por espaço para a conquista de seus direitos. Para tanto, o presente artigo pretende analisar as personagens que sofrem preconceito na narrativa "Aqueles dois", com o propósito de problematizar que o sentimento configurado entre os dois amigos não pode ser caracterizado como uma patologia ou uma transgressão da normalidade. Foi escolhida a narrativa em questão porque aborda a discriminação, podendo ser flagrados momentos de plena denúncia ao heterocentrismo e à homofobia. Assim, o conto relata como a sociedade reprime a demonstração de afeto entre pessoas do mesmo sexo, a incompreensão e negação ao presenciar o afeto entre dois homens. No texto não fica explícita a relação homoafetiva de Raul e Saul, porém a repressão que sofrem apenas por demonstrarem seus sentimentos, já caracteriza o toque de preconceito problematizado na narrativa.

Para compreender o conto em questão, faz-se necessário conhecer a biografia do autor. Caio Fernando Loureiro de Abreu nasceu em 1948, na cidade de Santiago, Rio Grande do Sul. Atuou nos principais jornais de seu estado, como o Zero Hora, e, também nos jornais mais renomados do país, como a Folha de São Paulo. Ele vivenciou uma época muito conturbada no país: a ditadura. Como intelectual e homossexual assumido, sofreu com a censura e, em 1968, começou a ser perseguido pelo DOPS (Departamento de Ordem Política e Social), tendo que se refugiar no sítio da amiga escritora, Hilda Hilst, e posteriormente, na Europa.

Considerando esse quadro, o objetivo deste trabalho é discutir o conto "Aqueles Dois" e explorar a questão do preconceito denunciado ao longo da obra. Nesse sentido, o texto de Caio Fernando Abreu vem para proporcionar uma experiência de humanização frente os dilemas culturais encontrados na sociedade.

\section{METODOLOGIA}

Para esse trabalho, serão utilizadas as pesquisas qualitativa e bibliográfica. Fonseca (2002) defende que a pesquisa bibliográfica é feita a partir do levantamento de referências teóricas já analisadas, e publicadas por meios escritos e eletrônicos. Ademais, afirma que qualquer trabalho científico inicia-se com uma pesquisa bibliográfica, pois esta proporciona ao pesquisador a chance de conhecer o que já foi estudado sobre o assunto. Segundo Lakatos (2010), o propósito da pesquisa bibliográfica é proporcionar ao pesquisador o contato direto com tudo o que foi escrito, dito ou filmado sobre determinado tema.

A pesquisa qualitativa, por sua vez, não enfoca a representatividade numérica, mas, sim, o aprofundamento da compreensão de um grupo social, de uma organização etc. Nessa linha, a pesquisa qualitativa está centralizada em aspectos da realidade que não podem ser quantificados, enfatizando a compreensão e explicação da dinâmica das relações sociais. Nessa linha, o presente artigo teve como meta abordar o conto "Aqueles Dois", de Abreu, tendo como foco o relacionamento entre as personagens protagonistas. Para tanto, a pesquisa contou com a contribuição teórica dos textos rubricados por Coelho (2000), Butler (2003) e, sobretudo, Candido (2013).

\section{RESULTADOS}

Na teoria literária são apresentados três tipos de narradores. Temos, em um polo, o narrador ausente do próprio relato, nomeado por Genette (1995, p. 243-244) como narrador heterodiegético. Em outro polo, situa-se o narrador presente na própria diegese, instituído como 
autodiegético. Há ainda o narrador heterodiegético, presente no relato, mas não na condição de protagonista.

O narrador autodiegético exprime-se em primeira pessoa, expondo uma ação que gira em torno de si próprio. Neste sentido, o narrador acumula a categoria de personagem protagonista, pois é aquele que narra as suas próprias experiências como personagem central da história. 0 narrador homodiegético pode narrar uma experiência pessoal, como personagem principal da história, ou na posição coadjuvante, ao narrar uma experiência da qual faz parte, no papel de observador ou testemunha. O narrador heterodiegético comporta-se como um demiurgo em relação à história que narra. Podendo ocorrer tanto em primeira pessoa quanto em terceira, sendo que a predominância é em terceira pessoa.

O narrador do conto em questão exprime-se na terceira pessoa. Ele é onisciente (sabe tudo sobre o relato) e onipresente (está presente em todos os lugares da história). Vemos a seguir um trecho que ilustra esse pensamento, quando o narrador pontua:

Há quase seis meses se conheciam. Saul deu-se bem com Carlos Gardel, que ensaiou um canto tímido ao cair da noite. Mas quem cantou foi Raul: "Perfídia", "La barca", "Contigo en la distancia" e, a pedido de Saul, outra vez, duas vezes, "Tu me acostumbraste". Saul gostava principalmente daquele pedacinho assim "sutil llegaste a mí como una tentación llenando de inquietud mi corazón". Jogaram algumas partidas de buraco e, por volta das nove, Saul se foi. $(2005$, p.89).

Nesse trecho, percebe-se a onisciência do narrador heterodiegético, pois além de narrar o que acontece com as personagens, ele também relata seus sentimentos. Portanto, conhece a intimidade das personagens e as explicita ao longo de seu discurso com riqueza de detalhes para criar um efeito de verossimilhança.

Ao analisar as personagens, percebe-se que Saul e Raul são personagens redondas ou esféricas, pois são dotadas de complexidade, apresentam características físicas e psicológicas. Segundo Reis e Lopes (1988) a personagem esférica é capaz de surpreender o leitor, suas características são construídas ao decorrer da narrativa. Ademais, as moças da repartição, os funcionários obesos, e também o chefe de seção, são todas caracterizadas como personagens planas, porque são personagens rasas e fáceis de compreender. De acordo com Reis e Lopes (1988) as personagens planas possuem um número limitado de atributos, sendo em geral, facilmente identificadas pelo leitor.

Devemos observar os nomes Raul e Saul, indicam a ideia de iguais, partes de um todo. De acordo com Andrade, F., Remundi, E., Souza, A. (2011) os nomes quase idênticos remetem-nos à ideia de que ambos seriam almas gêmeas. Desconstruindo a imagem de promiscuidade ou transgressão da natureza, frequentemente relacionada à relação homoafetiva, e indicando a pureza da relação entre as duas personagens. Para trazer à tona o caráter da personagem esférica, observa-se um trecho bastante curioso do conto $(2005$, p. 83$)$ : " Raul vinha de um casamento fracassado, três anos e nenhum filho. Saul, de um noivado tão interminável que terminara um dia, e um curso frustrado de arquitetura." As personagens, assim, recebem uma descrição minuciosa, evidenciando a sua complexidade frente as suspeitas levantadas pelos demais funcionários da repartição. Tal discriminação ganharia contornos ainda mais contundentes na sequência seguinte. Em uma noite, em razão de uma chuva, Saul dormiu no sofá do amigo, e, na manhã seguinte, foram juntos para o trabalho:

Dia seguinte, chegaram juntos à repartição, cabelos molhados do chuveiro. Nesse dia as moças não falaram com eles. Os funcionários barrigudos e desalentados trocaram alguns olhares que os dois não saberiam compreender, se percebessem. Mas nada perceberam, nem os olhares nem duas ou três piadas enigmáticas. (2005, p. 86 e 87). 
A homofobia manifesta-se de forma mais acentuada ao término do enredo, quando Raul e Saul são chamados pelo chefe de seção. O chefe vai direto ao ponto e relata que recebera cartas anônimas, o que pode ser visualizado no trecho seguinte:

Recusou-se a mostrá-las. Pálidos, os dois ouviram expressões como "relação anormal e ostensiva", "desavergonhada aberração", "comportamento doentio", "psicologia deformada", sempre assinadas por Um Atento Guardião da Moral. [...] antes que o chefe, depois de coisas como a-reputação-de-nossa-firma ou tenho-que-zelar-pela-moral-dosmeus funcionários, declarasse frio: os senhores estão despedidos. (2005, p. 88)'

O chefe demite os dois devido às declarações feitas por 'Um Atento Guardião da Moral'. Ressalta-se que eles não tiveram a chance de se defenderem nem de lutarem por seus direitos. Apenas aceitaram a decisão de seu superior e esvaziaram suas gavetas. Saul e Raul são demitidos simplesmente por terem um sentimento humano.

Nessa linha, a pesquisa em questão teve como resultados focalizar o preconceito da sociedade vigente durante a publicação do conto, em 1982. Ainda são vistos casos de preconceito e homofobia no contexto atual, resultando em diversos ataques de violência aos homossexuais. Segundo o levantamento realizado pelo Grupo Gay Bahia, em 2017, registrou-se que 445 lésbicas, gays, bissexuais, travestis e transexuais foram mortos vítimas de homofobia. $\mathrm{O}$ dado representa que ocorre uma morte a cada 19 horas. Portanto, foi registrado o maior número de mortes por homofobia desde que se iniciou o monitoramento pela entidade, há 38 anos.

Vemos a necessidade de continuar debatendo o tema de preconceito, visto que os ataques de violência motivados por algum preconceito continuam presentes em nossa sociedade. Tornase, portanto, fundamental a abordagem de tais atos de preconceito com o propósito de conscientizar o indivíduo e desenvolver o caráter humanizador em sua essência, tornando-o mais sensível à dor alheia.

\section{DISCUSSÃO}

A obra em questão é orquestrada de forma que rompe com os horizontes de expectativas do leitor, suprindo a necessidade de sentimentos que o leitor anseia, e tal necessidade é básica para o ser humano. Conforme Candido (1972) a literatura trata-se de uma força humanizadora, e não um sistema de obras. Logo, ela sensibiliza o homem e em seguida atua na sua própria formação.

Ao dissertar sobre essa nuance típica do texto literário, Lajolo (2001, p.122), diz:

[...] um livro tem é que renovar questões, recolocá-las de ângulos novos, refinar perguntas, aguçar curiosidades. 0 departamento das respostas é sempre território livre do leitor, senhor absoluto de sua cabeça e de sua vontade.

Para Lajolo (2001), a literatura tem o objetivo de, através da construção de palavras, organizar a desordem das mentes e corações. Portanto, a obra literária busca acalmar os ânimos do leitor, organizar suas ideias, sendo capaz de sensibilizar o destinatário, tocar o seu íntimo através da leitura e fazê-lo refletir sobre os problemas sociais. Além disso, o texto o transporta para o contexto social relatado na obra, para que ele sinta as questões que estão sendo debatidas e tenha anseio de igualmente manifestar-se.

De acordo com Candido (2013), a literatura abrange qualquer criação de toque poético, ficcional ou dramático em todos os níveis de uma sociedade, em todos os tipos de cultura, abordando desde folclore, lenda, chiste, até as mais complexas e difíceis produções escritas das grandes civilizações. Considerando a literatura como manifestação universal de toda a humanidade, em todas as eras, não é possível que um povo ou um indivíduo consigam viver sem ela, ou seja, sem a possibilidade de entrar em contato com alguma forma de fabulação, de fantasia, o uso da imaginação, a criação, o sonhar. O universo ficcional é necessário ao homem. 
Conclui-se que ninguém consegue viver sem o contato com o mundo imaginário, com a fabulação, a literatura trata-se de um direito universal que precisa ser satisfeito.

Ao dissertar sobre as concepções de literatura, Leite (2007) apresenta cinco concepções possíveis: a) A literatura como instituição nacional, como patrimônio cultural; b) A literatura como sistema de obras, autores e público; c) A literatura como disciplina escolar que se confunde com a história literária; d) Cada texto consagrado pela crítica como sendo literário; e) Qualquer texto, mesmo não consagrado, com intenção literária, visível num trabalho da linguagem e da imaginação, ou simplesmente esse trabalho enquanto tal.

Neste trabalho enfocaremos a última concepção. O objetivo é o uso da literatura como trabalho com a linguagem. Essa concepção mais ampla da literatura traz à tona possibilidades de uma educação diferente daquela proposta pela escola burguesa, capaz de criticar e transformar o modelo de sociedade que a sustenta. Tal conceito de trabalho não alienado ultrapassa a concepção convencional de literatura. A intenção é fomentar no indivíduo o anseio de transformar o mundo, e que por meio de sua ação, reconheça sua liberdade e escape à alienação. Assim, a literatura tem como princípio básico, o seu efeito revolucionário no leitor, capaz de causar mudanças. Ao mesmo tempo em que o humaniza e o sensibiliza, também o perturba, traz ao leitor ideias que antes eram desconhecidas, esse estranhamento o perturba e o instiga ao ato de mudança, de querer fazer a diferença, transformar o seu contexto social.

\section{CONCLUSÃO}

Através da análise realizada, foi possível perceber o preconceito denunciado na obra. Destaca-se o fim da narrativa, quando Saul e Raul são demitidos da firma por supostamente terem um comportamento inadequado. Percebe-se que a sociedade vigente na narrativa era incapaz de compreender o sentimento apresentado pelas duas personagens em questão, e devido à incompreensão, repreende tal ato. No contexto contemporâneo, surgem com mais frequência personagens homossexuais assumidos na televisão, filmes, mostrando seu cotidiano, o que torna essa realidade mais próxima das famílias, podendo fazer referência a algum parente ou amigo, desmitificando o tema. Portanto, faz-se necessária a discussão do tema, para que aconteça a inclusão de qualquer indivíduo no contexto social em que esteja inserido, independente de suas peculiaridades, estas que não devem interferir em sua aceitação no grupo. Pois o ser humano é caracterizado especialmente pelas diferenças, a sua identidade sexual, orientação sexual e tantos outros fatores não devem ser justificáveis para a exclusão de alguém de um meio social. As suas diferenças devem contribuir para a riqueza do grupo, tornando o grupo mais diversificado e ímpar.

\section{REFERÊNCIAS}

ABREU, Caio Fernando. Aqueles Dois. In. . Morangos mofados. Rio de Janeiro: Agir, 2005.

ANDRADE, F., REMUNDINI, E., SOUZA, A. Literatura, Homoafetividade e Respeito: uma leitura do conto Aqueles Dois, de Caio Fernando Abreu. Maringá: II Simpósio Internacional de Educação Sexual, 2011.

BAENA, Cristiane T. Literatura e vida literária em Caio Fernando Abreu: a escrita do irremediável. Rio de Janeiro: Ed. UERJ, 2008.

CANDIDO, A. A literatura e a formação do homem. In: Revista Ciência e Cultura. São Paulo: SBPC, 24 (9), set. 1972.

CANDIDO, A. Vários escritos. Rio de Janeiro: Ed. Ouro sobre Azul, 5a ed., 2013. 
COELHO, N. N. Literatura Infantil: teoria, análise, didática. São Paulo: Moderna, 1. ed., 2000.

FÁBIO, A.A trajetória e as conquistas do movimento LGBT brasileiro. Disponível em:

<https://www.nexojornal.com.br/explicado/2017/06/17/A-trajet\%C3\%B3ria-e-as-conquistas-domovimento-LGBT-brasileiro>. Acesso em 10 jul. 2018.

FONSECA, J. J. S. Metodologia da pesquisa científica. Fortaleza: UEC, 2002. Apostila.

GENETTE, Gérard. Discurso da narrativa. 3. ed. Lisboa: Vega, 1995.

LAKATOS, Eva Maria; MARCONI, Marina de Andrade. Fundamentos de metodologia científica. São Paulo: Ed. Atlas, 2010.

LAJOLO, M. Literatura: leitores e leitura. São Paulo: Moema, 2001.

REIS, C.; LOPES, A. M. Dicionário de teoria da narrativa. São Paulo: Ática, 1988.

VALENTE, J. Levantamento aponta recorde de mortes por homofobia no Brasil em 2017. Disponível em: <http://agenciabrasil.ebc.com.br/direitos-humanos/noticia/201801/levantamento-aponta-recorde-de-mortes-por-homofobia-no-brasil-em>. Acesso em 16 jul. 2018. 